Seki Öz, H., Ayhan, D., Söyünmez, S. / Journal of Yasar University, 2021, 16/61, 264-277

\title{
Sağlık Bilimleri Fakültesi Son Sınıf Öğrencilerinin Akademik Yeterlikleri ile Yaşamın Anlamı Arasındaki İlişki
}

\section{The Relationship Between Academic Competencies and Meaning of Life in Last Year Health Sciences Students}

\author{
Hilal SEKİ ÖZ, Kırşehir Ahi Evran Üniversitesi, Türkiye, hilalseki@hotmail.com \\ Orcid No: 0000-0003-2228-9805 \\ Didem AYHAN, Bandırma Onyedi Eylül Üniversitesi, Türkiye, kose.didem@gmail.com \\ Orcid No: 0000-0001-6687-6564 \\ Selin SÖYÜNMEZ, Kırşehir Ahi Evran Üniversitesi, Türkiye, selin_tardis@hotmail.com \\ Orcid No: 0000-0001-5671-6444
}

\begin{abstract}
Öz: Yaşamın anlamlarından biri olarak gösterilen akademik başarı üniversite eğitimi sırasında ön plana çıkmakta, ögrencilerin mesleki yeterliklere ve hayal ettikleri geleceğe kavuşmasına katkı sağlamaktadır. Araştırma Kırş̧ehir Ahi Evran Üniversitesi Hemşirelik, Ebelik ve Çocuk Gelişimi bölümlerinde son sinifta öğrenci olan 202 öğrenci ile gerçekleş̧tirilmiştir. Araştırmaya başlamadan önce kurum ve etik kurul izinleri alınmıştır. Araştırma verileri tanıtıcı bilgi formu, Akademik Öz Yeterlik Ölçeği ve Yaşam Tutum Profili Ölçeği ile Kasım 2020'de online olarak toplanmıştır. Veri analizleri SPSS 25.0 programında yapılmış, analizlerde tanımlayıcı istatistikler, Spearman korelasyon, Mann Whitney-U, Kruskal-Wallis analizleri kullanılmıştır. Öğrencilerin Akademik Öz Yeterlik Ölçeği

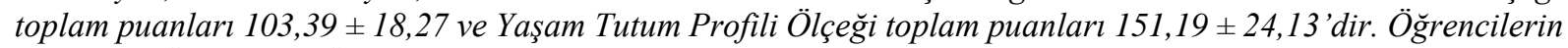
Akademik Öz Yeterlik Ölçeği puanlarının yaş, yaşanılan yer, gelir düzeyi, kardeş sayısı, anne-baba eğitim düzeyi ve bölümü isteyerek seçme değişkenlerine göre istatistiksel olarak anlaml bir fark olmadlğl; cinsiyet, bölüm ve akademik ilerleme isteme değişkenlerinde ise istatistiksel olarak anlamlı bir fark olduğu tespit edilmiştir. Yaşam Tutum Profili Ölçeği puanlarınınsa cinsiyet, yaş, bölüm, yaşanılan yer, gelir düzeyi, kardeş sayısı, anne-baba eğitim düzeyi ve bölümü isteyerek seçme değişkenlerine göre istatistiksel olarak anlamlı bir fark olmadlğı; akademik ilerleme isteme değişkeninde ise istatistiksel olarak anlaml bir fark olduğu tespit edilmiştir. Araştırmada Akademik Öz Yeterlik Ölçeği ile Yaşam Tutum Profili Ölçeği arasında zaylf, pozitif yönde anlamlı bir ilişki bulunmuştur $(r=0,358, p<0.001)$. Araştırma sonucunda öğrencilerin akademik öz yeterlikleri ile yaşama yükledikleri anlam arasında pozitif anlaml bir ilişsi olduğu saptanmıştır. Bu doğrultuda öğrencilerin akademik yeterliklerini geliștiren, yaşama yükledikleri anlamı sorgulamaların sağlayan eğitimlerin, derslerin eğitim sürecinde verilmesi ve etkinliğinin değerlendirildiği ileri düzey çalışmaların planlanması önerilmektedir.
\end{abstract}

Anahtar Kelimeler: Yaşamın Anlamı, Akademik Yeterlik, Hemşirelik, Ebelik, Çocuk Gelişimi

JEL Siniflandirmast: I10, I19, I20, I23, I29

Abstract: As one of the meanings of the course, success in the course contributes to the achievement of the university education, professional competencies and the future they dream of. The study was carried out with 202 last year students at Kirşehir Ahi Evran University Nursing, Midwifery and Child Development departments. Institutional and ethical board permissions were obtained before starting the research. The study was done using an online survey in November 2020. Data were collected using a Personal Information Form, the Academic SelfEfficacy Scale and the Life Attitude Profile Scale. Data were analyzed in SPSS 25.0 program. Descriptive statistics, Spearman correlation, Mann Whitney $U$, and Kruskal-Wallis test were used in data analysis. The students' Academic Self-Efficacy Scale was 103.39 18.27 and the total score of the Life Attitude Profile Scale was 151.19 \pm 24.13 . There was no statistically significant difference between the Academic Self-Efficacy Scale scores of the students according to the variables of age, place of residence, income level, number of siblings, education level of parents, and willingness to choose the department; A statistically significant difference was found in the variables of gender, department, and willingness about the academic progress. There is no statistically significant difference between the Life Attitude Profile Scale scores according to the variables of gender, age, department, place of residence, income level, number of siblings, education level of parents and willingness to choose the department; On the other hand, a statistically significant difference was found in the academic progress willing variable. In the study, a weak, positively significant relationship was found between Academic Self-Efficacy Scale and Life

Makale Gecmiși / Article History

Başvuru Tarihi / Date of Application Kabul Tarihi / Acceptance Date
: 18 Aralık/ December 2020

: 17 Ocak / January 2021 
Attitude Profile Scale $(r=0.358, p<0.001)$. It has been determined that there is a positive significant relationship between working hours academic self-efficacy and the meanings they attribute to life. In this direction, it is recommended to plan advanced studies that develop their educational competencies, evaluate the training of the trainings they impose on life, the training phase of the courses and their effectiveness.

Keywords: Meaning of Life, Academic Competence, Nursing, Midwifery, Child Development

JEL Classification: I10, I19, I20, I23, I29

\section{Giriş}

İnsanlık, varoluşundan beri kendisini ve çevresini anlamak için büyük bir arzu duymuş ve bitmeyen bir anlam arayışı içine girmiştir. Anlam, yaşamanın önemli olduğunu, günlerden ve yıllardan ibaret olmadığını hissetmeyi sağlayan ve arzu edilen geleceğe ulaşmak için planlamaları güdüleyen bağlantılardır (Akın ve Taş 2015). Yaşamın anlamını arama ve anlam oluşturma insanın kontrolünde bir olgu olup, sahip olunan değer ve inançlar çerçevesinde şekillenir. Benim için önemli olan nedir? sorusuna verilecek cevap değer ve inançları, dolayısıyla yaşamın anlamını ortaya koymaktadır (Tokur 2013). Yaşamı anlamlandırma süreci anlam arama çabalarını içinde barındıran, yaşam amaçlarıyla birlikte ele alınan, insan yaşamının doğal ve sağlıklı temel güdüsüdür. Birey yaşamının anlamını onun için değerli olan bir şey, bir duygu, bir durum, bir misyon ya da amaç gibi ifadelerle açıklayabiliyor ve yaşadığ 1 zor koşullara rağmen yaşamına az da olsa bir anlam verebiliyorsa, hayatta kalmak için bir güç bulabilmektedir (Altıntaş ve Gültekin 2004; Steger vd. 2006). Bu nedenle yaşamın anlamı yaşama devam edebilmek için bir güç ve kişiye özgü olma özelliği taşır (Yalom 2011).

Frankl (2020), yaşamın anlamını kazanmanın farklı yollardan elde edilebileceğini bu yollardan birinin eser yaratmak ya da bir iş yapmak olduğunu öne sürmektedir. Her insanın yaşamında özel bir mesleği veya uğruna çaba harcanacak bir misyonu, yerine getirilmesi gereken görevleri vardır (Ergezen 2004). İnsanlar bu görevlerini yerine getirmede başarılı oldukları, idealleri ve değerleri uğruna yaşadıkları müddetçe içsel motivasyonlarını koruyabilir ve yaşamlarından haz alabilirler. Yapılan araştırmalarda, yüksek ekonomik gelir ve akademik başarının yaşamdan alınan haz ile ilişkili olduğu (Aydıner 2011; Diener ve Biswas-Diener 2002; Yıkılmaz ve Demir Güdül 2015); mesleğin ve başarılı olmanın yaşamın anlamı için önemli etkenler olduğu belirtilmektedir (Baş ve Hamarta 2015; Steger vd. 2006). Yaşamda başarılı olmak göreceli bir değerlendirme olup bireyin yaşına, bulunduğu çevreye, kişilik özelliklerine ve daha birçok nedenlere bağlı olarak farklılaşmaktadır (Calp ve Bacanlı 2016). Başarılı olmak, yaşamın anlamlı olması ve yaşamın anlamının ifade edilebilmesi bireyin algıladığı ölçüde farklılaşmasıyla beraber akademik başarıyla da ilişkilendirilmektedir (Bond ve Feather 1988; Boswell 2018) 
Yaşamın anlamlarından biri olarak gösterilen akademik başarı spesifik olarak bireyin eğitiminde başarılı olması, kendini akademik olarak yeterli bulması ve başarının ölçütü olarak bu durumun genel akademik not ortalamasına (GANO) yansımasıdır (Bakan ve Güler 2017). Üniversite eğitimi içinde akademik olarak başarılı olmanın standart ölçütleri olmayıp diploma almaya hak kazanan her öğrencinin başarılı olduğu söylenebilir. Öğrenciler arasında 'sorumlu olunan derslerden geçmek', 'okulu uzatmamak', 'mesleğe dair tüm yeterlikleri kazanmak' gibi değerlendirmeler yapılabilse de oldukça kişisel bir yorumlama olduğu açıktır. Bazı öğrenciler için başarı; 'bütünlemeye kalmadan dersten geçmek' olabilirken, bazı öğrenciler için 'GANO sıralamasında ilk üç içinde yer almak' şeklinde olabilmektedir (Calp ve Bacanlı 2016). Ayrıca öğrencilerin okulda iyi bir performans sergilemeleri için akademik bir hedef belirlemeleri, bunun için zaman ayırmaları ve emek vermeleri gerekmektedir. $\mathrm{Bu}$ nedenle hedeflerine ulaşabilmeleri için yaşamda anlam duygusuna sahip olmanın istedikleri akademik başarı için faydalı olacağı düşünülmektedir (Kokkinos, Kargiotidis, ve Markos 2015). Yaşama anlam yükleyen öğrencilerin hedefe yönelik olduğu, zamanlarını daha planlı ve amaçlarına yönelik kullandıkları, zekâ, sorumluluk ve öz disipline daha fazla değer verdiği (Bond ve Feather 1988; Boswell 2018; Steger vd. 2006), hayatlarını bir misyon ve amaç olarak algıladıkları görülmektedir (Steger vd. 2006). Karma yöntemlerle yapılan bir araştırmada üniversite öğrencilerinin çoğunluğunun yaşamlarının anlamını belirsiz olarak tanımladığı ve hala yaşamın anlamını aradıkları, bunun yanında eğitim hayatının öğrenciler için önemli bir yaşam anlamı kaynağı olduğuna dikkat çekilmektedir (Mason 2013). Yaşamın anlamı akademik katılım ve okul başarısı ile ilişkilendirilmiş (Greenway 2006), yüksek akademik başarıya sahip öğrencilerin, düşük akademik başarıya sahip olan öğrencilere göre yaşama daha fazla anlam yükledikleri belirtilmektedir (Boswell 2018; Nackord 1983).

Üniversite öğrencileri arasında hasta/sağlıklı her yaştan bireye yaşamın başlangıcından sonuna kadar hizmet sunmaları nedeniyle hemşirelik, ebelik ve çocuk gelişimi gibi bölümlerin öğrencilerinin akademik yeterliliği önemli olmakta, bu durum toplum sağlı̆̆ının korunması ve geliştirilmesinde kritik rol oynayabilmektedir. Bu bölümlerde okuyan öğrenciler yaşamın her döneminde insana yaşam yolculuğunda eşlik etmekte ve yaşama yükledikleri anlamın bu eşlik etme sürecini olumlu ya da olumsuz etkileyebileceği düşünülmektedir. Akademik yeterlik algısı, bireylerin yaşama verdikleri anlam ile ilişkili olmakta, bu durumun sağlık alanında hizmet sunan bölümlerde okuyan öğrencilerin bilgi, beceri, tutum ve davranışlarına yansıyan sonuçları bulunmaktadır. Lisans eğitimini tamamlamaya yakın olan son sınıf öğrencilerinin, diğer sınıflardaki öğrencilere göre hem eğitim sürecinde hedeflenen mesleki yetkinliklerin çoğunluğunu kazanmış olması, hem de gelecekteki meslek yaşantısını nasıl şekillendireceğine 
dair öngörülerini ve planlamalarını oluşturmuş olması beklenmektedir. $\mathrm{Bu}$ öğrencilerin mesleklerini icra etme biçimlerini ve dolaylı olarak toplumun sağlık düzeyini etkileyecek değişkenler olarak akademik öz yeterlik ve yaşama yüklediği anlam arasındaki ilişkinin ve bunları etkileyen faktörlerin araştırması önem kazanmaktadır. Literatür incelendiğinde akademik yeterliliğe yönelik çalışmalar bulunsa da sağlık bilimleri alanındaki öğrencilerin yaşama yükledikleri anlama yönelik çalışmalara rastlanmamıştır. Bu bağlamda, araştırmada sağlık bilimleri fakültesi hemşirelik, ebelik ve çocuk gelişimi bölümü son sınıf öğrencilerinin, akademik yeterlikleri ile yaşama verdikleri anlam arasındaki ilişkinin incelenmesi amaçlanmıştır.

\section{Gereç ve Yöntem}

$\mathrm{Bu}$ çalışma, sağlık bilimleri fakültesi son sınıf öğrencilerinin akademik yeterlikleri ve yaşama verdikleri anlam arasındaki ilişkiyi belirlemek amacıyla tanımlayıcı ve analitik olarak planlanmiştır.

\subsection{Araştırmanın Evreni ve Örneklemi}

Araştırmanın evrenini Kırşehir Ahi Evran Üniversitesi Sağlık Bilimleri Fakültesinde Hemşirelik, Ebelik ve Çocuk Gelişimi olarak üç bölüm bulunmaktadır. Bu bölümlerde son sınıfta okuyan sırasıyla 160, 60 ve 60 öğrenci olup, toplam 280 öğrenci araştırmanın evrenini oluşturmaktadır. Araştırmaya son sınıf öğrencilerinin seçilmesinin nedeni akademik yeterlik algısı ve GANO ölçümleri için eğitimlerini tamamlamaya yakın olmaları ve lisans eğitimlerine, beklentilerine dair öz değerlendirmelerini daha etkin yapabilecek durumda olmalarının düşünülmesidir. Araştırmada örneklem seçimine gidilmemiş olup evrenin tamamına ulaşılması hedeflenmiştir. Araştırmaya sağlık bilimleri fakültesinde okuyan, aktif öğrenci kaydı olan, son sınıf öğrencisi olan ve araştırmaya katılmaya gönüllü olan öğrenciler dahil edilirken bu özellikleri taşımayan öğrenciler dahil edilmemiştir. Araştırmaya katılmaya gönüllü olan 205 öğrenciden 3'ünün kayıp verisi olduğundan 202 öğrenci örneklemi oluşturmuştur. Araştırmanın verileri 01.11.2020- 30.11.2020 tarihleri arasında, online olarak toplanmıştır.

\subsection{Veri Toplama Araçları}

Verilerin toplanmasında literatürde yer alan bilgiler doğrultusunda araştırmacılar tarafından hazırlanan tanıtıcı bilgi formu, Akademik Öz Yeterlik Ölçeği ve Yaşam Tutum Profili Ölçeği kullanılmıştır.

Tanıtıcı bilgi formu: Çalışmaya katılan öğrencilerin yaşı, cinsiyeti, aile tipi, anne babasının eğitim durumları, ekonomik durumları, kardeş sayısı, okudukları bölümü tercih etme sebepleri 
ve isteyerek seçip seçmedikleri, genel ağırlıklı not ortalamalarının yer aldığı toplam 14 sorudan oluşmaktadır.

Akademik Öz Yeterlik Ölçeği (AÖYÖ): Owen ve Froman (1988) tarafından geliştirilen ölçeğin Türkçe uyarlaması Ekici (2012) tarafından yapılmıştır. 5'li likert tipte olan ölçek 33 sorudan oluşmakta ve tersten puanlanan soru bulunmamaktadır. Ölçek sosyal statü, bilişsel ve teknik beceriler olmak üzere toplam 3 alt boyuttan oluşmaktadır. Ölçekten alınabilecek en düşük puan 33, en yüksek puan ise 195 'tir. Yapılan geçerlik güvenirlik çalışmasında ölçeğin Cronbach $\alpha$ iç tutarlılık kat sayısı 0,86 olarak bulunmuştur. Bu araştırmada ise ölçeğin Cronbach $\alpha$ iç tutarlılık kat sayısı 0,82 çıkmıştır.

Yaşam Tutum Profili Ölçeği (YTPÖ): Peacock ve Reker (1982) tarafından geliştirilmiş olan ölçeğin Türkçe'ye uyarlanması Erci (2008) tarafından yapılmıştır. Toplam 30 maddeden oluşan ölçek 7'li likert tiptedir. Ölçeğin, yaşamın amacı, yaşamın anlamı, yaşama dair seçim /sorumluluk ve yaşamın anlamını araştırma olmak üzere 4 alt boyutu vardır. Ölçekten alınabilecek en düşük puan 30, en yüksek puan ise 210 'dur. Yapılan bu çalışmada ölçeğin Cronbach $\alpha$ iç tutarlılık kat sayısı 0,91 olarak ifade edilmiştir. Bu araştırmada ise ölçeğin Cronbach $\alpha$ iç tutarlılık kat sayısı 0,82 olarak bulunmuştur.

\subsection{Verilerin Analizi}

$\mathrm{Bu}$ çalışmada istatistiksel analiz için SPSS 25.0 istatistik programı kullanılmıştır. Ölçek iç tutarlıkları için Cronbach $\alpha$ kat sayısı, tanımlayıcı verilerin analizinde sayı, yüzdelik dağılım, ortalama, standart sapma kullanılmıştır. Verilerin normal dağılıma uyup uymadığı Kolmogorow-Smirnov testi ile değerlendirilmiştir. Normal dağılıma uymadığı için nonparametrik testler tercih edilmiş ve Spearman korelasyon, Mann Whitney U, Kruskal-Wallis analizleri kullanılmıştır. İstatistiksel anlamlılık düzeyi $\mathrm{p}<0,05$ olarak belirlenmiştir.

\subsection{Araștırmanın Etik Yönü}

Çalışmanın etik ilkelere uygunluğu Kırşehir Ahi Evran Üniversitesi Klinik Araştırmalar Etik Kurulu tarafından değerlendirilmiş ve 06.10.2020 tarih 2020-14/107 sayılı etik onam alınmıştır. Veriler Helsinki bildirgesine uygun şekilde katılımcı onamları alınarak çevrimiçi olarak toplanmıştır.

\section{Araştırmanın Sinırlılıkları}

Araştırmanın tek bir merkezde yürütülmüş olması, sağlık bilimlerine ilişkin bölümlerin kısıtlı sayıda olması ve bölümlerin öğrenci sayısının benzer dağılmaması sınırlılıkları arasında sayılabilir. 


\section{Bulgular}

Araştırmaya dahil edilen öğrencilere ilişkin; demografik özellikler, akademik öz yeterlik ve yaşam tutum profili ölçeklerine ilişkin puanlar ve bu değişkenlerin birbiri ilişkisi belirlenmiştir.

Tablo 1. Araştırmaya katılan bireylerin sosyo-demografik özellikleri ve AÖYÖ ve YTPÖ ortalama puanları $(n=202)$

\begin{tabular}{|c|c|c|c|c|c|c|c|}
\hline & & $\mathbf{N}$ & $\%$ & $\begin{array}{c}\text { AÖYÖ } \\
\text { ORT } \pm \text { SD }\end{array}$ & $\mathbf{p}$ & $\begin{array}{c}\text { YTPÖ } \\
\text { ORT } \pm \text { SD }\end{array}$ & $\mathbf{p}$ \\
\hline \multirow{2}{*}{ Cinsiyet } & Kadın & 167 & 82,7 & $105,58 \pm 18,32$ & \multirow{2}{*}{$\begin{array}{c}<0,001 \\
Z:-3,970\end{array}$} & $152,01 \pm 22,06$ & \multirow{2}{*}{$\begin{array}{c}0,909 \\
Z:-0,115\end{array}$} \\
\hline & Erkek & 35 & 17,3 & $92,94 \pm 14,10$ & & $147,28 \pm 32,36$ & \\
\hline \multirow{3}{*}{ Bölüm } & Çocuk gelişimi & 52 & 25,7 & $111,32 \pm 20,35$ & \multirow{3}{*}{$\begin{array}{c}0,001 \\
\text { KW:14,811 }\end{array}$} & $151,82 \pm 24,97$ & \multirow{3}{*}{$\begin{array}{c}0,076 \\
\mathrm{KW}: 5,165\end{array}$} \\
\hline & Ebelik & 54 & 26,7 & $103,09 \pm 17,03$ & & $147,00 \pm 21,79$ & \\
\hline & Hemşirelik & 96 & 47,5 & $99,27 \pm 16,44$ & & $153,19 \pm 24,13$ & \\
\hline \multirow{3}{*}{$\begin{array}{c}\text { Yaşanılan } \\
\text { Yer }\end{array}$} & İl & 105 & 52,0 & $104,03 \pm 18,42$ & \multirow{3}{*}{$\begin{array}{c}0,456 \\
\mathrm{KW}: 1,572\end{array}$} & $151,07 \pm 23,64$ & \multirow{3}{*}{$\begin{array}{c}0,741 \\
\text { KW:0,599 }\end{array}$} \\
\hline & İlçe & 67 & 33,2 & $104,64 \pm 19,33$ & & $153,11 \pm 22,14$ & \\
\hline & Köy & 30 & 14,9 & $98,36 \pm 14,72$ & & $147,30 \pm 29,86$ & \\
\hline \multirow{2}{*}{ Aile tipi } & Çekirdek aile & 164 & 81,2 & $103,94 \pm 19,12$ & \multirow{2}{*}{$\begin{array}{c}0,590 \\
Z:-0,538\end{array}$} & $151,10 \pm 24,84$ & \multirow{2}{*}{$\begin{array}{c}0,635 \\
Z:-0,474\end{array}$} \\
\hline & Diğer & 38 & 18,8 & $101,01 \pm 13,98$ & & $151,55 \pm 21,09$ & \\
\hline \multirow{4}{*}{$\begin{array}{c}\text { Anne } \\
\text { eğitim } \\
\text { durumu }\end{array}$} & İlkokula gitmemiş & 36 & 17,8 & $99,05 \pm 16,20$ & \multirow{4}{*}{$\begin{array}{c}0,550 \\
\mathrm{KW}: 2,110\end{array}$} & $150,00 \pm 28,48$ & \multirow{4}{*}{$\begin{array}{c}0,164 \\
\mathrm{KW}: 5,107\end{array}$} \\
\hline & Ortaöğretim & 134 & 66,3 & $103,61 \pm 18,76$ & & $151,02 \pm 23,10$ & \\
\hline & Lise & 26 & 12,9 & $107,96 \pm 19,20$ & & $156,46 \pm 25,07$ & \\
\hline & Üniversite & 6 & 3,0 & $104,83 \pm 18,27$ & & $139,16 \pm 7,52$ & \\
\hline \multirow{4}{*}{$\begin{array}{c}\text { Baba } \\
\text { eğitim } \\
\text { durumu }\end{array}$} & İlkokula gitmemiş & 3 & 1,5 & $107,66 \pm 6,80$ & \multirow{4}{*}{$\begin{array}{c}0,480 \\
\text { KW:2,474 }\end{array}$} & $156,66 \pm 11,67$ & \multirow{4}{*}{$\begin{array}{c}0,094 \\
\text { KW:6,399 }\end{array}$} \\
\hline & Ortaöğretim & 114 & 56,4 & $102,26 \pm 16,94$ & & $150,41 \pm 25,09$ & \\
\hline & Lise & 61 & 30,2 & $106,18 \pm 17,86$ & & $156,47 \pm 20,74$ & \\
\hline & Üniversite & 24 & 11,9 & $101,16 \pm 25,21$ & & $140,79 \pm 25,81$ & \\
\hline \multirow{3}{*}{$\begin{array}{c}\text { Kardeş } \\
\text { sayısı }\end{array}$} & 1 & 5 & 2,5 & $101,20 \pm 17,13$ & \multirow{3}{*}{$\begin{array}{c}0,858 \\
\mathrm{KW}: 0,306\end{array}$} & $136,20 \pm 25,50$ & \multirow{3}{*}{$\begin{array}{c}0,157 \\
\text { KW:3,707 }\end{array}$} \\
\hline & $2-3$ & 110 & 54,5 & $103,02 \pm 18,83$ & & $153,20 \pm 22,92$ & \\
\hline & 4 ve üzeri & 87 & 43,1 & $103,98 \pm 17,78$ & & $149,50 \pm 25,37$ & \\
\hline \multirow{3}{*}{$\begin{array}{c}\text { Kardeş } \\
\text { sıralaması }\end{array}$} & İlk & 61 & 30,2 & $100,14 \pm 17,18$ & \multirow{3}{*}{$\begin{array}{c}0,288 \\
\mathrm{KW}: 2,493\end{array}$} & $151,91 \pm 22,92$ & \multirow{3}{*}{$\begin{array}{c}0,845 \\
\mathrm{KW}: 0,338\end{array}$} \\
\hline & Ortanca & 91 & 45,0 & $104,67 \pm 18,93$ & & $150,08 \pm 25,53$ & \\
\hline & Son & 50 & 24,8 & $105,04 \pm 18,17$ & & $152,32 \pm 23,32$ & \\
\hline \multirow{5}{*}{$\begin{array}{c}\text { Gelir } \\
\text { durumu }\end{array}$} & 2000 ve altı & 38 & 18,8 & $104,10 \pm 17,16$ & & $151,07 \pm 23,60$ & \\
\hline & $2001-3000$ & 60 & 29,7 & $104,11 \pm 19,12$ & & $147,48 \pm 26,42$ & \\
\hline & $3001-4000$ & 52 & 25,7 & $102,46 \pm 17,19$ & $\begin{array}{c}0,991 \\
\mathrm{KW} \cdot 0156\end{array}$ & $156,69 \pm 23,06$ & $\begin{array}{c}0,291 \\
\mathrm{KW} \cdot 4007\end{array}$ \\
\hline & $4001-5000$ & 37 & 18,3 & $102,51 \pm 18,82$ & & $152,40 \pm 21,88$ & \\
\hline & 5001 ve üzeri & 15 & 7,4 & $104,13 \pm 21,82$ & & $144,26 \pm 23,43$ & \\
\hline Bölümü & Evet & 160 & 79,2 & $103,94 \pm 19,38$ & 0,592 & $149,99 \pm 25,20$ & 0,226 \\
\hline & Hayır & 42 & 20,8 & $101,30 \pm 13,20$ & $\mathrm{Z}:-0,536$ & $155,76 \pm 19,11$ & $\mathrm{Z}:-1,212$ \\
\hline & Sevme & 114 & 56,4 & $104,37 \pm 19,26$ & & $152,11 \pm 22,91$ & \\
\hline & İş bulma & 46 & 22,8 & $104,30 \pm 18,89$ & & $149,30 \pm 29,98$ & \\
\hline Tercih & Aile isteği & 21 & 10,4 & $102,00 \pm 13,91$ & $\begin{array}{c}0,450 \\
\mathrm{KW} \cdot 3644\end{array}$ & $153,76 \pm 17,85$ & $\begin{array}{r}0,188 \\
K W \cdot 6158\end{array}$ \\
\hline & Tesadüf & 10 & 5,0 & $95,80 \pm 17,79$ & KW:3,044 & $160,00 \pm 14,58$ & KW:b,158 \\
\hline & Sene kayb1 & 11 & 5,4 & $99,00 \pm 11,92$ & & $136,63 \pm 23,36$ & \\
\hline Akademik & Evet & 138 & 68,3 & $107,69 \pm 17,47$ & $<0,001$ & $154,82 \pm 21,36$ & 0,004 \\
\hline ilerleme & Hayır & 64 & 31,7 & $94,12 \pm 16,53$ & $\mathrm{Z}:-4,750$ & $143,35 \pm 27,82$ & $\mathrm{Z}:-2,849$ \\
\hline & Çocuk gelişimi & & $\mathrm{ORT} \pm \mathrm{S}$ & $=3,32 \pm 0.29$ & & & \\
\hline & Ebelik & & $\mathrm{ORT} \pm \mathrm{S}$ & $=3,04 \pm 0,28$ & & -0 - & \\
\hline
\end{tabular}




\begin{tabular}{|c|c|c|}
\hline & Hemşirelik & $\mathrm{ORT} \pm \mathrm{SD}=2,88 \pm 0,28$ \\
\hline Yaş & & $\mathrm{ORT} \pm \mathrm{SD}=22,40 \pm 2,179$ \\
\hline
\end{tabular}

Tablo 1 incelendiğinde çalışmaya katılan öğrencilerin yaş ortalaması 22,40 22,179 , \%82,72'nin kadın, 47,5'inin hemşirelik bölümünde okuduğu, \%52'si il merkezinde ve \%81,2'si çekirdek aile düzeninde yaşadığı. \%66,3'ünün annesinin \%56,4'ünün de babasının ortaöğretim mezunu olduğu. \%54,5'inin 2 ya da 3 kardeş, \%45'inin de ortanca çocuk olduğu. \%29,7'sinin gelir düzeyinin 2001-3000 TL arasında olduğu, \%79,'sinin okudukları bölümü isteyerek tercih ettikleri, \%56,4'ünün sevdiği için bu tercihi yaptığ1, \%68,32' ünün akademik olarak ilerlemek

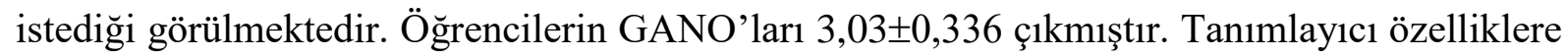
göre ölçeklerden alınan puan ortalamaları karşılaştırıldığında, çalışmaya katılan kadın

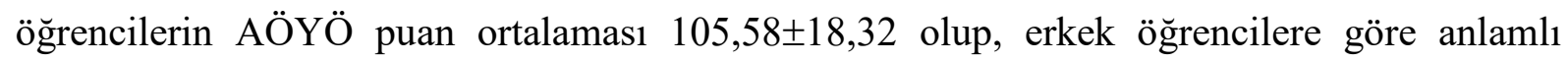
derecede yüksek çıkmıştır ( $p<0,001)$. Çocuk gelişimi bölümünde okuyan öğrencilerin AÖYÖ puan ortalaması $111,32 \pm 20,35$ 'tir. Ebelik ve hemşirelik bölümünde okuyan öğrencilerin bu ölçekten aldıkları puana göre anlamlı derecede yüksek olduğu görülmektedir $(p<0,05)$.

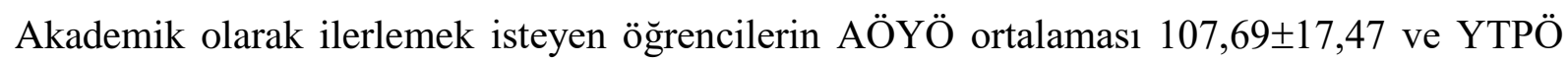
puan ortalaması $154,82 \pm 21,36$ çıkmıştır ve bu puan akademik olarak ilerlemek istemeyen öğrencilerden anlamlı biçimde yüksektir $(\mathrm{p}<0,05)$.

Tablo 2. AÖYÖ toplam ve alt ölçek puan ortalamaları

\begin{tabular}{lccc}
\hline Ölçek- Alt Ölçekler & ORT \pm SD & $\begin{array}{c}\text { Ölçekten alınan alt ve } \\
\text { üst değerler }\end{array}$ & $\begin{array}{c}\text { Ölçeğin alt ve üst } \\
\text { değerleri }\end{array}$ \\
\hline Sosyal Statü Boyutu & $40,18 \pm 8,25$ & $11-48$ & $10-50$ \\
\hline Bilişsel Boyut & $62,78 \pm 10,98$ & $27-91$ & $19-95$ \\
\hline Teknik Beceriler Boyutu & $11,57 \pm 3,13$ & $4-20$ & $4-20$ \\
\hline $\begin{array}{l}\text { Akademik Öz Yeterlik Ölçeği } \\
\text { Toplam }\end{array}$ & $103,39 \pm 18,27$ & $43-156$ & $33-195$ \\
\hline
\end{tabular}

Öğrencilerin AÖYÖ alt boyutları ve ölçek toplam puanı tablo 2'de yer almaktadır. Sosyal statü alt boyut puanı $40,18 \pm 8,25$, Bilişsel alt boyut puanı $62,78 \pm 10,98$, Teknik Beceriler alt

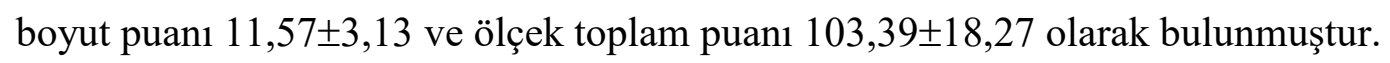


Tablo 3. YTPÖ toplam ve alt ölçek puan ortalamaları

\begin{tabular}{lccc}
\hline Ölçek- Alt Ölçekler & ORT \pm SD & $\begin{array}{c}\text { Ölçekten alınan alt } \\
\text { ve üst değerler }\end{array}$ & $\begin{array}{c}\text { Ölçeğin alt ve üst } \\
\text { değerleri }\end{array}$ \\
\hline Yaşamın Amacı Boyutu & $40,18 \pm 8,25$ & $11-56$ & $8-56$ \\
\hline Yaşamın Anlamı Boyutu & $34,69 \pm 5,95$ & $13-49$ & $7-49$ \\
\hline $\begin{array}{l}\text { Yaşama Dair Seçim /Sorumluluk } \\
\text { Boyutu }\end{array}$ & $41,87 \pm 8,47$ & $17-56$ & $8-56$ \\
\hline Yaşamın Anlamını Araştırma Boyutu & $40,44 \pm 7,58$ & $7-49$ & $7-49$ \\
\hline Yaşam Tutum Profili Toplam & $151,19 \pm 24,13$ & $54-203$ & $30-210$ \\
\hline
\end{tabular}

Öğrencilerin YTPÖ alt boyutları ve ölçek toplam puanı tablo 3'de yer almaktadır. Yaşamın Amacı alt boyut puanının 40,18 $\pm 8,25$, Yaşamın Anlamı alt boyut puanının 34,69 $\pm 5,95$, Yaşama

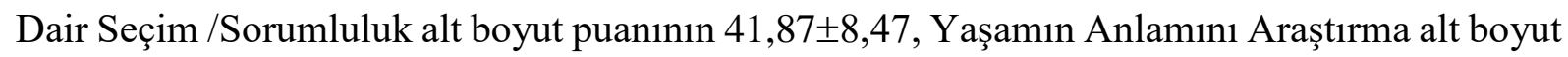

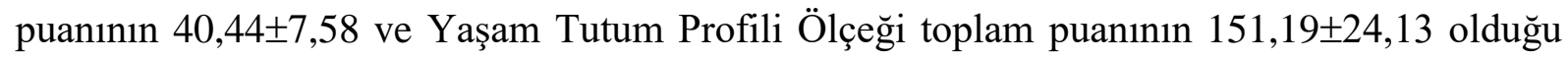
görülmektedir.

Grafik 1. AÖYÖ ve YTPÖ saçılım grafiği

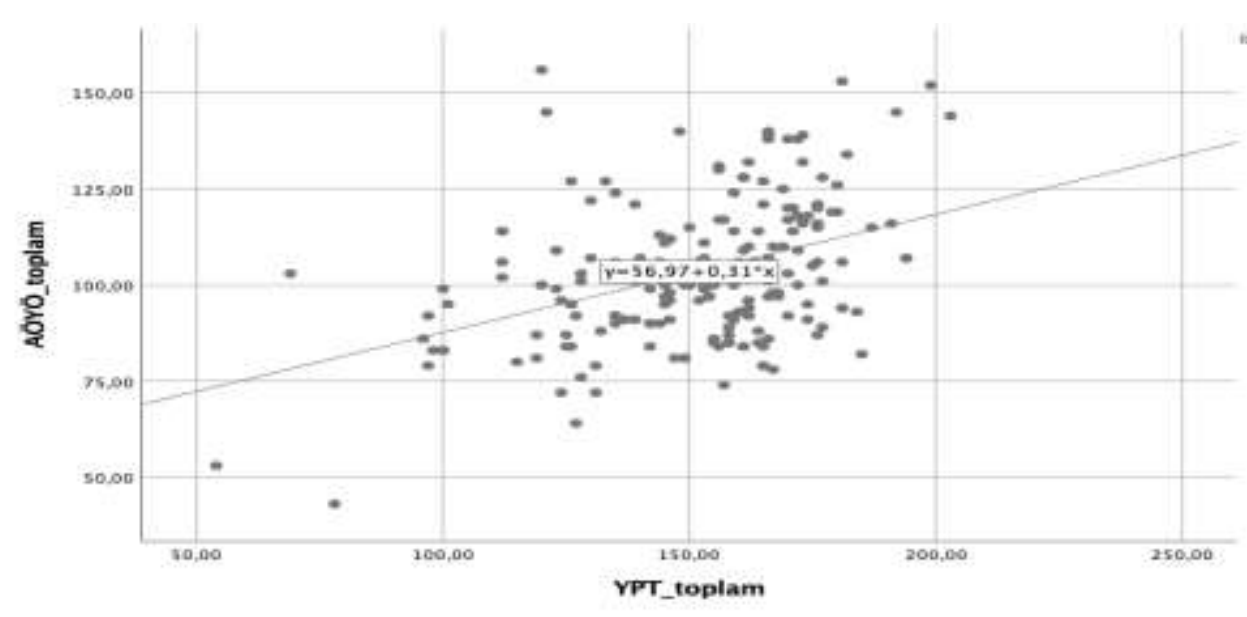

Öğrencilerin AÖYÖ ile YTPÖ toplam puanları arasındaki korelasyon Grafik 1'de yer almaktadır. Analiz sonucunda AÖYÖ ile YTPÖ arasında zayıf düzeyde ve pozitif yönde anlamlı bir ilişki bulunmuştur $(r=0,358, \mathrm{p}<0,001)$ (Grafik 1).

Tablo 4. AÖYÖ VE YTPÖ Toplam ve Alt Ölçekler Arasındaki İlişki

\begin{tabular}{|c|c|c|c|c|c|c|c|c|c|c|}
\hline & 1 & 2 & 3 & 4 & 5 & 6 & 7 & 8 & 9 \\
\hline \multirow{4}{*}{$\begin{array}{l}0 \\
0 \\
0\end{array}$} & $\begin{array}{l}\text { 1.Sosyal } \\
\text { Statü }\end{array}$ & & $\begin{array}{l}0,598 \\
<0,001\end{array}$ & $\begin{array}{l}0,505 \\
<0,001\end{array}$ & $\begin{array}{l}0,829 \\
<0,001\end{array}$ & $\begin{array}{l}0,256 \\
<0,001\end{array}$ & $\begin{array}{l}0,180 \\
<0,001\end{array}$ & $\begin{array}{l}0,229 \\
<0,001\end{array}$ & $\begin{array}{l}0,265 \\
<0,001\end{array}$ & $\begin{array}{l}0,286 \\
<0,001\end{array}$ \\
\hline & 2.Bilişsel & & & $\begin{array}{l}0,551 \\
<0,001\end{array}$ & $\begin{array}{l}0,920 \\
<0,001\end{array}$ & $\begin{array}{l}0,356 \\
<0,001\end{array}$ & $\begin{array}{l}0,307 \\
<0,001\end{array}$ & $\begin{array}{l}0,340 \\
<0,001\end{array}$ & $\begin{array}{l}0,194 \\
<0,001\end{array}$ & $\begin{array}{l}0,358 \\
<0,001\end{array}$ \\
\hline & $\begin{array}{l}\text { 3.Teknik } \\
\text { Beceriler }\end{array}$ & & & & $\begin{array}{l}0,692 \\
<0,001\end{array}$ & $\begin{array}{l}0,214 \\
0,002\end{array}$ & $\begin{array}{l}0,181 \\
0,010\end{array}$ & $\begin{array}{l}0,211 \\
0,003\end{array}$ & $\begin{array}{l}0,165 \\
0,019\end{array}$ & $\begin{array}{l}0,219 \\
0,002\end{array}$ \\
\hline & $\begin{array}{l}\text { 4.AÖYÖ } \\
\text { Toplam }\end{array}$ & & & & & $\begin{array}{l}0,342 \\
<0,001\end{array}$ & $\begin{array}{l}0,281 \\
<0,001\end{array}$ & $\begin{array}{l}0,326 \\
<0,001\end{array}$ & $\begin{array}{l}0,243 \\
<0,001\end{array}$ & $\begin{array}{l}0,358 \\
<0,001\end{array}$ \\
\hline & $\begin{array}{l}\text { 5.Yaşamın } \\
\text { Amacı }\end{array}$ & & & & & & $\begin{array}{l}0,641 \\
<0,001\end{array}$ & $\begin{array}{l}0,673 \\
<0,001\end{array}$ & $\begin{array}{l}0,358 \\
<0,001\end{array}$ & $\begin{array}{l}0,864 \\
<0,001\end{array}$ \\
\hline
\end{tabular}




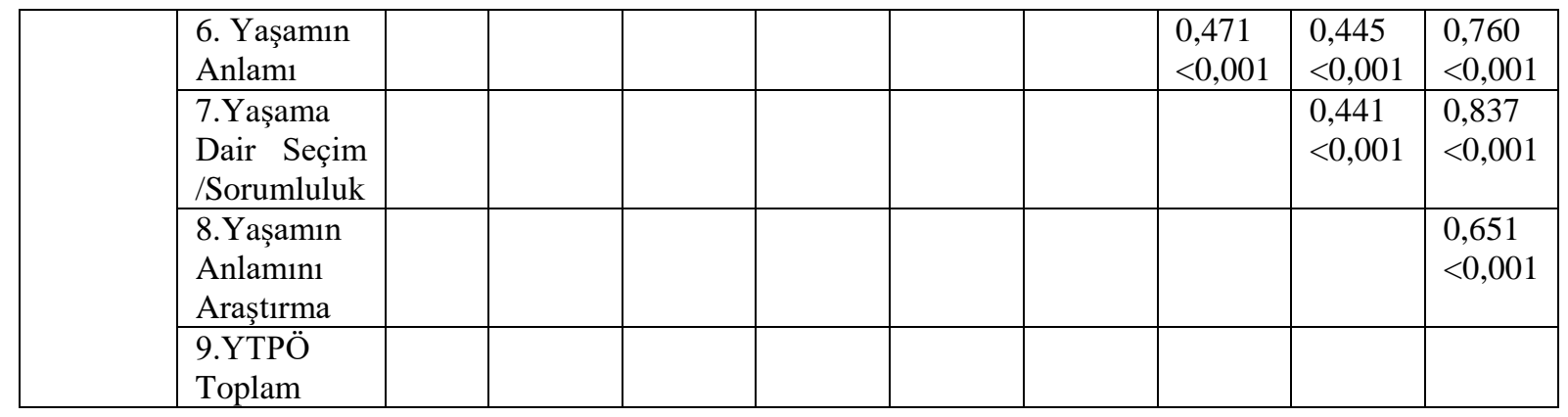

AÖYÖ alt boyutlarından sosyal statü puanının YTPÖ alt boyutlarından yaşamın amacı $(\mathrm{r}=0,256, \mathrm{p}<0,001)$, yaşamın anlamı $(\mathrm{r}=0,180, \mathrm{p}<0,001)$, yaşama dair seçim /sorumluluk $(\mathrm{r}=0,229, \mathrm{p}<0,001)$, yaşamın anlamını araştırma $(\mathrm{r}=0,265, \mathrm{p}<0,001)$ ve YTPÖ toplam puanı $(\mathrm{r}=0,286, \mathrm{p}<0,001)$ arasında pozitif yönlü anlamlı bir ilişki vardır. AÖYÖ alt boyutlarından bilişsel puanının YTPÖ alt boyutlarından yaşamın amacı $(r=0,356, p<0,001)$, yaşamın anlamı $(\mathrm{r}=0,307, \mathrm{p}<0,001)$, yaşama dair seçim /sorumluluk $(\mathrm{r}=0,340, \mathrm{p}<0,001)$, yaşamın anlamını araştırma $(r=0,194, p<0,001)$ ve YTPÖ toplam puanı $(r=0,358, p<0,001)$ arasında pozitif yönlü anlamlı bir ilişki vardır. AÖYÖ alt boyutlarından teknik beceriler puanının YTPÖ alt boyutlarından yaşamın amacı $(r=0,214, p=0,002)$, yaşamın anlamı $(r=0,181, p=0,010)$, yaşama dair seçim /sorumluluk ( $r=0,211, p=0,003)$, yaşamın anlamını araştırma $(r=0,165, p=0,019)$ ve YTPÖ toplam puanı $(r=0,219, \mathrm{p}=0,002)$ arasında pozitif yönlü anlamlı bir ilişki vardır.

\section{Tartışma}

$\mathrm{Bu}$ araştırma ile sağlık bilimleri fakültesi son sınıf öğrencilerinin, akademik yeterlikleri ve yaşama verdikleri anlam arasındaki ilişkinin incelenmesi amaçlanmıştır.

Çalışmada tanımlayıcı özelliklere göre ölçeklerden alınan puan ortalamaları karşılaştırıldığında, çalışmaya katılan kadın öğrencilerin AÖYÖ puan ortalaması, erkek öğrencilere göre anlamlı derecede yüksek çıkmıştır $(p<0,001)$. Literatürde kadın ve erkek öğrencilerin öz yeterliklerini ölçen ölçme araçlarına karşı farklı algı ve tutumlara sahip olabileceği, erkek egemen toplumlarda meslekte başarılı olma misyonunun erkeklere yüklenmesinden ya da çeşitli klişeleşmiş inançlardan dolayı erkek öğrencilerin bu tür ölçümlerde öz yeterliklerini daha fazla algılayarak bildirdiği, kadın öğrencilerin ise orta düzeyde bildirimde bulundukları belirtilmektedir (Schunk ve Pajares 2002). Yapılan çalışmalarda erkek öğrencilerin öz yeterliklerinin kadın öğrencilere göre daha yüksek olduğu (Fırat Durdukoca 2010; Terzi ve Mirasyedioğlu 2009), bir başka çalışmada ise benzer bir şekilde erkek öğrencilerin akademik öz yeterlik puanlarının kadın öğrencilerden fazla olduğu ifade edilmiştir (Akbay ve Gizir 2010). Bazı araştırmalarda ise cinsiyet ve akademik öz yeterlik arasında anlamlı bir fark görülmemiştir (Akbaş ve Çelikkaleli 2006; Yenice 2012; Yılmaz vd. 
2006). Telef ve Karaca (2012), Arslan (2017, 2018)'ın araştırmalarına göre akademik öz yeterliğin kadın öğrencilerde daha fazla olduğu belirtilmiştir. Literatürde cinsiyet değişkenine yönelik farklı sonuçlar olduğu görülmektedir. Araştırmadan elde edilen sonuçlara göre kadın öğrencilerin akademik öz yeterlik puan ortalamaları, erkek öğrencilere göre daha fazla bulunmuştur. $\mathrm{Bu}$ durumun çalışma kapsamına alınan bölümlerde öğrenci yetiştirilen mesleklerin kadın yoğun meslekler olması, hasta bakımı, bebek doğumu ve çocuğun gelişimi gibi kadının geleneksel rolleri üzerine temellenmesi, kadın öğrencilerin bu bölümleri daha severek-isteyerek seçmesi ve akademik olarak kendilerini daha yeterli bulması sonucunda ortaya çıktığı söylenebilir.

Araştırma bulgularına göre öğrencilerin kayıtlı oldukları bölüm ile akademik öz yeterlikler arasında anlamlı bir fark olduğu, çocuk gelişimi bölümünde okuyan öğrencilerin akademik özyeterlik puanlarının diğer bölümlerde okuyan öğrencilerden daha yüksek olduğu belirlenmiştir. Satıcı'nın (2013) 1679 üniversite öğrencisi ile yaptığı bir çalışmada öğrencilerin eğitim aldıkları alan ile akademik yeterlik arasında anlamlı bir fark olmadığı saptanmıştır. Eroğlu ve arkadaşlarının (2017) spor bilimleri fakültesi öğrencileriyle yaptıkları çalışmada öğrencilerin bölüm değişkenlerine göre akademik öz yeterliğin istatistiksel olarak anlamlı bir fark göstermediği saptanmıştır. Bandura’ya göre (1996) verilen görevin zorluk derecesi, ortama ilişkin bazı faktörler ve öğrencilerin mevcut bilgisi ve altyapısı öz-yeterliği etkiler ve öz yeterlilik temel olarak kişisel başarı algısına dayanmaktadır. Akademik öz yeterliğin akademik başarı üzerindeki etkisinin incelendiği çalışmada akademik öz yeterlik ile akademik başarı ilişkili bulunmuştur (Honicke ve Broadbent, 2016). Yenilmez ve Kakmacı'nın (2008) yaptıkları çalışmada yüksek not ortalaması olan öğrencilerin öz yeterlik inanç düzeylerinin, not ortalaması düşük olan öğrencilere göre daha yüksek olduğu gösterilmiştir. Başka bir çalışmada ise akademik başarının, akademik öz-yeterlik inançları üzerinde anlamlı değişikliğe sebep olduğu ifade edilmiş ve akademik başarı puanı yüksek olan öğrencilerin akademik öz-yeterlik inanç puanlarının da yüksek olduğu ortaya koyulmuştur (Tunca ve Alkın-Şahin, 2014). Bu doğrultuda akademik öz yeterlik algısının, üniversite öğrencisinin başarı göstergesi olan GANO'dan etkilendiği söylenebilir. Çalışmada ortaya çıkan farklılığın çocuk gelişimi, ebelik ve hemşirelik bölümündeki öğrencilerin GANO puanlarıyla uyumlu olduğu, çocuk gelişimi öğrencilerinin en yüksek GANO’ya sahip olmalarının akademik öz yeterlik algısının yüksek olmasına katkı sağladığ1 söylenebilir. Ayrıca sağlık bilimleri fakültesi bünyesinde bulunan bu üç alanın mesleki beceri, rol ve sorumluluklar açısından ayrıştığı görülmektedir. Öğrencilerin birer sağlık profesyoneli adayı olmaları ile birlikte mesleki rollerinin, eğitim müfredatının ve ders içeriklerinin farklı olması, hemşirelik ve ebelik bölümlerinde eğitim alan öğrencilerin sağlık 
alanında karmaşık, teknik bilgi ve becerileri öğrenme gerekliliğinin bulunmasından kaynaklandığı söylenebilir.

Araştırma bulgularına göre öğrencilerin akademik olarak ilerleme istekleri ile akademik yeterlikleri ve yaşam anlamları arasında anlamlı bir fark olduğu bulunmuştur. Literatürde akademik ilerleme isteğinin bir güdüleyici faktör olarak öğrencilerin akademik yeterliklerini etkileyebildiği yönünde çalışmalar bulunmaktadır (Deci ve Ryan 2000; Özdemir 2020). Akademik ilerleme isteği güdüleyen bir faktör olarak öğrenme süreçlerine katkı sağlamakta, akademik başarıyı ve öz yeterliği arttırmaktadır (Komarraju ve Dial 2014; Eymur ve Geban 2012; Huang 2011). Ayrıca akademik ilerleme sarf etmek isteyen öğrencilerin yaşam tutum ölçeği puanları da yüksek bulunmuştur. Yaşamın anlamı kişiden kişiye değişebilmekte ve özellikle meslek edinmenin bir adım öncesi olan üniversite döneminde önem kazanmaktadır. Üniversite öğrencilerinde yaşamın anlamının araştırıldığı bir çalışmada eğitimin, yaşamın anlamının kaynaklarından biri olduğu bildiilrmiştir (Mason 2013). Başka bir çalışmada akademik başarısı düşük olan öğrencilerin akademik başarısı yüksek olan öğrencilere göre yaşama daha az anlam yükledikleri belirtilmiştir (Boswell 2018). Lisansüstü eğitim yapma arzusu akademik başarıyı ön koşul kılarak akademik ilerleme için gerekli olduğundan, öğrencilerin kendilerine bir hedef edinmesinin yaşamlarına anlam katmalarına katkıda bulunduğu, bu yüzden akademik olarak ilerlemek isteyen öğrencilerin öz yeterliliklerini daha yüksek ve yaşamalarını daha anlamlı hale getirdikleri söylenebilir.

Araştırmada AÖYÖ ile YTPÖ arasındaki ilişki incelendiğinde zayıf, pozitif yönde anlamlı bir ilişki bulunmuştur $(\mathrm{r}=0,358, \mathrm{p}<0.001)$. Üniversite öğrencilerinin yaşam amaçlarının alt boyutlarının genel öz-yeterlik arasındaki ilişkinin incelendiği bir araştırmada yaşam amaçları ile genel öz-yeterlik arasında pozitif yönde ilişki saptanmıştır (Aydıner 2011). Başka bir çalışmada bireylerin yaşam amaçlarına ulaşmaya dair gösterdikleri çabaların, yaşam bağlılığının önemli göstergelerinden biri olan yaşam anlamını güçlendirdiği saptanmıştır (Kansu ve Hızlı Sayar 2018). Başka bir çalışmada öğrencilerin yaşam anlam düzeyi yükseldikçe yaşama yön verilerek, verimli bir yaşam yaşayabildikleri bulunmuştur (Parlak 2014). Öğrencilerin yaşama yüklediği anlam akademik okul başarısı ile ilişkilendirilmiş, akademik başarısı yüksek düzeyde olan öğrencilerin, düşük olanlara göre yaşama daha anlamlı buldukları belirtilmiştir (Greenway 2006; Boswell 2018). Çalışma verileri ile literatür bilgileri uyumlu olup, akademik öz yeterlik ve yaşam anlamı arasında ilişki olduğu, öğrencilerin kendilerini akademik olarak yeterli bulma düzeylerinin yaşama yüklediği anlamı pozitif yönde etkilediği söylenebilir. 


\section{Sonuç}

Sağlık bilimleri fakültesinde okuyan ve eğitimlerinin son yılında olan öğrencilerin akademik öz yeterlikleri ile yaşama yükledikleri anlam arasında ilişkiyi inceleyen bu çalışmada, öğrencilerin kendilerini akademik olarak yeterli bulma durumları ile yaşama yükledikleri anlam arasında pozitif anlamlı bir ilişki olduğu, akademik olarak ilerlemek isteyen öğrencilerin kendilerini daha yeterli ve yaşamlarını daha anlamlı buldukları saptanmıştır. Akademik öz yeterlik algısı kadın öğrencilerde erkeklere göre daha yüksek çıkmıştır. Bölüm değişkenine göre ise çocuk gelişimi bölümünde okuyan öğrencilerin daha yüksek düzeyde akademik öz yeterlikleri olduğu bulunmuştur. Toplum sağlığının korunması ve geliştirilmesinde önemli rollere sahip meslek mensuplarını yetiştiren bölümlerde okuyan öğrencilerin başarı düzeylerinin artmasının akademik öz yeterliğe, akademik ilerleme gibi yaşam amaçlarının varlığı ise yaşama yüklenen anlamın artmasına etki ettiği, bu sayede daha kaliteli sağlık meslek mensuplarının yetiştirilebileceği söylenebilir. $\mathrm{Bu}$ bağlamda öğrencilerin akademik yeterliklerini geliştiren, yaşama yükledikleri anlamları sorgulamalarını, kendilerini bu yönde geliştirmelerini sağlayacak derslerin, eğitimlerin verilmesi ve bu eğitimlerin etkisinin değerlendirildiği daha ileri düzey çalışmaların yapılması önerilmektedir. 


\section{KAYNAKÇA}

Akbaş, Ahmet, ve Öner Çelikkaleli. 2006. "Sınıf Öğretmeni Adaylarının Fen Öğretimi ÖzYeterlik İnançlarının Cinsiyet, Öğrenim Türü ve Üniversitelerine Göre İncelenmesi”. Mersin Üniversitesi Eğitim Fakültesi Dergisi 2 (1): 98-110. https://doi.org/10.17860/efd.53326.

Akbay, Sinem Evin, ve Cem Ali Gizir. 2010. "Cinsiyete Göre Üniversite Öğrencilerinde Akademik Erteleme Davranışı: Akademik Güdülenme, Akademik Özyeterlik ve Akademik Yükleme Stillerinin Rolü’. Mersin Üniversitesi Eğitim Fakültesi Dergisi 6 (1): 60-78. https://doi.org/10.17860/efd.38518.

Akın, Ahmet, ve İbrahim Taş. 2015. "Yaşam Anlamı Ölçeği: Geçerlik ve Güvenirlik Çalışması". Journal of Turkish Studies 10 (3): 27-36. https://doi.org/10.7827/turkishstudies.7860.

Altıntaş, Ersin, ve Mücahit Gültekin. 2004. Psikolojik Danışma Kuramları. 1. baskı. Bursa: Alfa Aktüel Yayınları.

Arslan, Aysel. 2017. "Ortaokul Öğrencilerinin Okuma Kaygıları ve Akademik Özyeterlik İnançlarının Çeşitli Değişkenler Açısından İncelenmesi” 1 (1): 12-31.

2018. "Ortaokul öğrencilerinin yazma kaygıları ve akademik öz-yeterlik inançlarının çeşitli değişkenler açısından incelenmesi”. Abant İzzet Baysal Üniversitesi Ĕ̌itim Fakültesi Dergisi, 1818 (3): 1286-1312.

Aydıner, Berent Burcu. 2011. "Üniversite Öğrencilerinin Yaşam Amaçlarının Alt Boyutlarının Genel Öz-Yeterlik Yaşam Doyumu ve Çeşitli Değişkenlere Göre İncelenmesi”. Sakarya Üniversitesi.

Bakan, Ismail, ve Bilge Güler. 2017. "Duygusal Zekânın, Yaşam Doyumu ve Akademik Başarıya Etkileri ve Demografik Özellikler Bağlamında Algı Farklılıkları”. Sosyal ve Ekonomik Arastırmalar Dergisi 19 (33): $1-11$.

http://ezproxy.umgc.edu/login?url=https://www.proquest.com/docview/1990750215?accountid=14580 \%0Ahttp://sfx.umd.edu/uc?url_ver=Z39.88-

2004\&rft_val_fmt=info:ofi/fmt:kev:mtx:journal\&genre=article\&sid=ProQ:ProQ\%3Aabiglobal\&atitle= Duygusal+Zek\%26acirc\%3Bnın\%2C+Y.

Bandura, Albert, Barbaranelli, Claudio, Caprara, Gian V. ve Concetta Pastorelli. 1996. "Multifaceted impact of self-efficacy beliefs on academic functioning". Child Development. 67:1206-1222.

Baş, Veysi, ve Erdal Hamarta. 2015. "The Correlation between Values and the Meaning of Life of University Students”. Değerler Ĕgitimi Dergisi 13 (29): 369-91. http://dergipark.gov.tr/ded/issue/29167/312340.

Bond, Micheal J., ve Norman T. Feather. 1988. "Some Correlates of Structure and Purpose in the Use of Time". Journal of Personality and Social Psychology 55 (2): 321-29. https://doi.org/10.1037/00223514.55.2.321.

Boswell, Kwoneathia Rasha. 2018. "The role of study strategy use, meaning in life, and grit on the academic success of university students." The University of Mississippi. http://libezp.lib.lsu.edu/login?url=http://search.ebscohost.com/login.aspx?direct=true\&db=psyh\&AN=2 017-19717-271\&site=ehost-live\&scope=site.

Calp, Şükran, ve Hasan Bacanlı. 2016. "Algılanan Akademik Yeterlik ve Özerklik Desteğinin Özerk Akademik Motivasyon ve Akademik Başarıla İlişkisi”. Mehmet Akif Ersoy Üniversitesi Eğitim Fakültesi Dergisi 1 (40): 300-317. https://doi.org/10.21764/efd.47706.

Deci, Edward L., ve Richard M. Ryan. 2000. "The 'what' and 'why' of goal pursuits: Human needs and the selfdetermination of behavior". Psychological Inquiry 11 (4): 227-68. https://doi.org/10.1207/S15327965PLI1104_01.

Diener, Ed, ve Rpbert Biswas-Diener. 2002. "W1ll Money Increase Subjectıve Well-Beıng?” Social Indicators Research, say1 57: 119-69.

Ekici, Gülay. 2012. “Akademik Öz Yeterlilik Ölçeği: Türkçeye Uyarlama, Geçerlilik ve Güvenilirlik Çalışması.” Hacettepe Üniversitesi Ĕgitim Fakültesi Dergisi 43: 174-85.

Erci, Behice. 2008. "Meaning in life for patients with cancer: Validation of the Life Attitude Profile-Revised Scale". Journal of Advanced Nursing 62 (6): 704-11. https://doi.org/10.1111/j.1365-2648.2008.04658.x.

Ergezen, Efsun. 2004. "Günümüz Ateisterinde Hayatı Anlamlandırma”. Ankara Üniversitesi.

Eroğlu, Oğuzhan, Yıldırım, Yunus ve Hasan Şahan. 2017. "Spor Bilimleri Fakültesindeki Öğrencilerin Akademik Öz-Yeterlik ve Akademik Güdülenme Düzeyleri Arasındaki İlişkinin İncelenmesi: Akdeniz Üniversitesi Örneği". Türkiye Spor Bilimleri Dergisi. 1 / 1:38-47.

Eymur, Gülüzar, ve Ömer Geban. 2012. "Kimya Öğretmeni Adaylarının Motivasyon ve Akademik Başarıları Arasındaki İlişkinin İncelenmesi”. Hacettepe Üniversitesi Eğitim Fakültesi Dergisi 43: 174-85.

Fırat Durdukoca, Şule. 2010. "SSınıf Öğretmen Adaylarının Akademik Özyeterlik Algılarının Çeşitli Değişkenler Açısından İncelenmesi”. Abant İzzet Baysal Üniversitesi Dergisi Cilt:10 10 (1): 69-77.

Frankl, Victor E. 2020. İnsanın Anlam Araylşı. Editör Çev. Selçuk Budak. 73. İstanbul: Okuyan Us Yayınları.

Greenway, Kimberly A. 2006. "The Role of Spirituality in Purpose in Life And Academic Engagement”. Journal of College and Character 7 (6): 0-5. https://doi.org/10.2202/1940-1639.1212.

Huang, Chiungjung. 2011. "Self-concept and academic achievement: A meta-analysis of longitudinal relations". Journal of School Psychology 49 (5): 505-28. https://doi.org/10.1016/j.jsp.2011.07.001.

Honicke, Toni, ve Jaclyn Broadbent. 2016. "The influence of academic self-efficacy on academic performance: A 
systematic review." Educational Research Review 17: 63-84.

Kansu, Ayça Ferda, ve Gökben Hızlı Sayar. 2018. "Öz yeterlik, yaşam anlami ve yaşam bağliliği kavramlari üzerine bir inceleme”. Üsküdar üniversitesi Illetişim Fakültesi Akademik Dergisi 1 (1): 78-89.

Kokkinos, Constantinos M., Apostolos Kargiotidis, ve Angelos Markos. 2015. "The relationship between learning and study strategies and big five personality traits among junior university student teachers". Learning and Individual Differences 43: 39-47. https://doi.org/10.1016/j.lindif.2015.08.031.

Komarraju, Meera, ve Christopher Dial. 2014. "Academic identity, self-efficacy, and self-esteem predict selfdetermined motivation and goals". Learning and Individual Differences 32: 1-8. https://doi.org/10.1016/j.lindif.2014.02.004.

Mason, Henry D. 2013. "Meaning in life within an African context: A mixed method study". Journal of Psychology in Africa 23 (4): 635-38. https://doi.org/10.1080/14330237.2013.10820679.

Nackord, Ernest J. 1983. "A College Test of Logotherapeutic Concepts". The International Forum for Logotherapy, 6 (2): 117-22.

Owen, Steven V, ve Robin D Froman. 1988. "Development of a College Academic Self-Efficacy". National Council on Measurement in 8 Education, https://files.eric.ed.gov/fulltext/ED453254.pdf\%0Ahttps://files.eric.ed.gov/fulltext/ED290864.pdf\#page $=668$.

Özdemir, Petek Akman. 2020. "Türkiye'de Yapılan Araştırmalarda Akademik Güdülenme ile Akademik ÖzYeterlik Arasındaki İlişki: Bir Meta-Analiz Çalışması”. Içinde EJERCongress 2020 Bildiri Kitabl, 71730 .

Anı

Yayıncilik. https://www.researchgate.net/profile/Petek_Akman_Oezdemir/publication/346563905_Turkiye'de_Yap ilan_Arastirmalarda_Akademik_Gudulenme_ile_Ak̄ademik_Oz-Yeterlik_Arasindaki_Iliski_Bir_MetaAnaliz_Calismasi/links/5fc76d7f299bf188d4e90235/Tuerkiyede-Yapilan-Arastirmalarda-AkademikGueduelenme-ile-Akademik-Oez-Yeterlik-Arasindaki-Iliski-Bir-Meta-Analiz-Calismasi.pdf.

Parlak, Simel. 2014. "Yüksek Öğrenim Kredi Yurtlar Kurumunda Barınan Kız Öğrencilerin Yaşam Anlam Düzeyleri İle Psikolojik Dayanıklılıkları Arasındaki İlişki (İstanbul Örneği)”. Marmara Üniversitesi.

Peacock, Edward J, ve Gary T Reker. 1982. "The Life Attitude Profile ( LAP ): further evidence of reliability and empirical validity." 14 (1).

Satıcı, Seydi Ahmet. 2013. "Üniversite öğrencilerinin akademik öz-yeterliklerinin çeşili değişkenler açısından incelenmesi". MS thesis. Anadolu Üniversitesi.

Schunk, Dale H., ve Frank Pajares. 2002. "the Development of Academic Advising Programs". Development of achievement motivation. Academic Press, 15-31. https://doi.org/10.1016/B978-012750053-9/50003-6.

Steger, Michael F., Patricia Frazier, Matthew Kaler, ve Shigehiro Oishi. 2006. "The meaning in life questionnaire: Assessing the presence of and search for meaning in life". Journal of Counseling Psychology 53 (1): 8093. https://doi.org/10.1037/0022-0167.53.1.80.

Telef, Bülent Baki, ve Rengin Karaca. 2012. "Çocuklar İçin Öz-Yeterlik Ölçeği; Geçerlik Ve Güvenirlik Çalışması”. Buca Eğitim Fakültesi Dergisi 32: 169-87.

Terzi, Mustafa, ve Şeref Mirasyedioğlu. 2009. “İlköğretim Matematik Öğretmen Adaylarının Matematiğe Yönelik Özyeterlik Algılarının Bazı Değişkenler Açısından İncelenmesi”. TÜBAV Bilim Dergisi 2 (2): 257-65.

Tokur, Behlül. 2013. “Gaye- Anlam Bağlamında Kendini Gerçekleştirmek”. Atatük Üniversitesi İlahiyat Fakültesi Dergisi, say1 40: 149-62.

Tunca, Nihal, ve Senar Alkın-Şahin. 2014. "Öğretmen adaylarının bilişötesi (üst biliş) öğrenme stratejileri ile akademik öz yeterlik inançları arasındaki ilişki." Anadolu Üniversitesi Ë̆itim Bilimleri Enstitüsü Dergisi. 4.1: 47-48.

Yalom, Irvin. 2011. Varoluşçu Psikoterapi. Editör Çev. Zeliha İyidoğan Babayiğit. İstanbul: Kabalcı Yayınevi.

Yenice, Nilgün. 2012. “Öğretmen Adaylarının Öz-Yeterlik Düzeyleri İle Problem ÇözBecerilerinin İncelenmesi”. Elektronik Sosyal Bilimler Dergisi 11 (39): 36-58. https://doi.org/10.17755/esosder.99419.

Yenilmez, Kürşat, ve Özlem Kakmac1. 2008. "İlköğretim matematik öğretmenliği bölümü öğrencilerinin öz yeterlilik inanç düzeyleri." Eskişehir Osmangazi Üniversitesi Sosyal Bilimler Dergisi. 9.2: 1-21.

Yıkılmaz, Murat, ve Meryem Demir Güdül. 2015. "Üniversite Öğrencilerinde Yaşam Doyumu, Yaşamda Anlam ve Bilinçli Farkındalık Arasındaki İlişkiler”. Ege Ĕ̆itim Dergisi 16 (2): 297-315.

Yılmaz, Miraç, Cem Gerçek, Pınar Köseoğlu, ve Haluk Soran. 2006. "Hacettepe Üniversitesi biyoloji öğretmen adaylarının bilgisayarla ilgli öz-yeterlik inançlarının incelenmesi”. Hacettepe Üniversitesi Ĕ̈itim Fakültesi Dergisi, sayı 30: 278-87. 